\title{
Propagation Medium Moisture Level Influences Adventitious Rooting of Woody Stem Cuttings
}

\author{
William H. Rein', Robert D. Wright ${ }^{2}$, and. John R. Seiler ${ }^{3}$ \\ Virginia Polytechnic Institute and State University, Blacksburg, VA 24061-0327 \\ Additional index words. juniperus horizontalis, Blue Rug juniper, Rhododendron, azalea, Ilex crenata, 'Helleri' holly, \\ water potential
}

Abstract. Stem cuttings of Blue Rug juniper (Juniperus horizontalis Moench 'Wiltonii'), 'Hino-Crimson' azalea [ Rhododendron (Lindl.) P1anch 'Hino-Crimson'], and 'Helleri' holly (Ilex crenata Thunb. 'Helleri') were propagated in 1 peat : 1 perlite $(\mathrm{v} / \mathrm{v})$ at one of five moisture levels based on medium dry weight $(125 \%, 250 \%, 375 \%, 500 \%$, or $625 \%)$. Cutting survival and percentage of rooted cuttings were highest at the highest medium moisture level in all three species. Incidence of cutting basal rot was not directly related to medium moisture level, but more to the growth stage of the stock plant. Midday xylem water potential ( $(\boldsymbol{\Psi})$ ) of cuttings for each species was highest in the wettest propagation medium and lowest in the driest medium. During propagation, stem cutting $\boldsymbol{\psi}$ below $-2.0 \mathrm{MPa}$ occurred even in the wettest medium tested, and frequently reached $-4.0 \mathrm{MPa}$ in cuttings in the driest treatment (125\%). Basal water uptake by cuttings was highest in the wettest medium moisture level. Water uptake was highest during the first few days after insertion, and thereafter decreased until root emergence.

Intermittent mist systems are commonly used to reduce transpirational water loss from cuttings during propagation. A problem with this system is maintaining a wet leaf surface without overwetting the rooting medium. Water and air compete for pore space in a medium (Loach, 1985), and oxygen availability may be reduced as the volume of water in the medium is increased. Studies of various media have revealed that physical characteristics of media, such as particle size, are less deterministic of rooting performance than are air and water content (Long, 1933; Tilt and Bilderback, 1987). Soffer and Burger (1988) found that Ficus benjamina and Dendranthema $\times$ grandiflorum cuttings rooted best when their aqueous rooting medium was saturated with oxygen $\left(\approx 8 \mathrm{mg} \cdot\right.$ liter $\left.^{-1}\right)$ and did not root when the medium oxygen concentration was zero. Thus, the lack of oxygen in an overwet medium may cause propagation failure.

Cut stems will absorb water from the propagation medium despite limitations to water movement by internal stem resistances and lack of roots (Grange and Loach, 1983). Incomplete contact of the stem cutting base with the film of water surrounding the medium particles can be a major source of uptake resistance. Water uptake by stem cuttings may be directly proportional to the water content of the propagation medium (Loach, 1985). If transpiration exceeds water uptake, cutting turgidity will be reduced. Cuttings may rehydrate to full turgidity overnight - when the vapor pressure deficit is normally reduced-provided the propagation medium is sufficiently moist (Grange and Loach, 1983). If the propagation medium is insufficiently moist, full hydration of cuttings may not occur, limiting propagation success.

Because few quantitative data exist defining the optimum levels of moisture in a propagation medium (Tilt and Bilderback, 1987), propagators face a dilemma in providing adequate but not excessive moisture to stem cuttings both above and below the medium surface. The objective of this study was to determine the influence of a range of moisture levels in the propa-

\footnotetext{
Received for publication 6 Apr. 1990. The cost of publishing this paper was defrayed in part by the payment of page charges. Under postal regulations, this paper therefore must be hereby marked advertisement solely to indicate this fact.

'Former Graduate Student, Dept. of Horticulture.

${ }^{2}$ Professor, Dept. of Horticulture.

Assistant Professor, Dept. of Forestry.
}

gation medium on the $\psi$, adventitious rooting, quality, and survival of stem cuttings of Blue Rug juniper, 'Hino-Crimson' azalea, and 'Helleri' holly.

\section{Materials and Methods}

Treatment establishment. Five medium moisture levels- $125 \%$, $250 \%, 375 \%, 500 \%$, or $625 \%$ water $(\mathrm{w} / \mathrm{w})$ - were established for a steam-pasteurized mix of 1 sphagnum peat : 1 coarse perlite $(\mathrm{v} / \mathrm{v})$ that had been sieved to pass through a $5.7-\mathrm{mm}$ mesh screen. Individual $2.9 \times 10.4 \mathrm{~cm}(50 \mathrm{ml})$ translucent plastic centrifuge tubes (Nalge Co., Sybron Corp., Rochester, $\mathrm{N}$. Y.) were filled with the medium with uniform compaction. Water was applied to each tube until a specific moisture level (determined gravimetrically) was reached. Cuttings were inserted into the tubes as described below for each species.

To maintain the medium moisture levels, each cutting-tube unit was weighed every 4 days, and water was injected with a syringe through the Parafilm into the medium to compensate for water loss. To differentiate between water losses due to cutting uptake and evaporative losses from the medium, $0.5 \times 12 \mathrm{~cm}$ wooden dowels, treated like stem cuttings, were placed in randomized complete blocks (RCB) among the cuttings on the propagation bench. Therefore, stem cutting water uptake data is the amount of water lost from the cutting-tube unit minus that from the dowel-tube unit at each date.

Comparison of the tested range of medium moisture with typical propagation conditions. Tubes of the peat/perlite medium, if placed under intermittent mist (on-time $8 \mathrm{sec}$ every $8 \mathrm{~min}$ ) with tops left uncovered and the tube bases perforated for drainage, would equilibrate at $400 \%$ to $500 \%$ moisture by dry weight. Therefore, the highest medium moisture level tested, $625 \%$, is greater than the level of moisture found in the same medium at an equivalent depth and volume under standard intermittent mist conditions. The $625 \%$ moisture-treatment tubes contained excess free water that would have drained from the tubes had they been perforated.

Blue Rug juniper. On 27 Feb. 1989, 15-cm-long stem tip cuttings were taken from Juniperus horzontalis 'Wiltonii' (Blue Rug juniper) growing in a residential landscape in Blacksburg, Va. The cuttings were trimmed acropetally to $13 \mathrm{~cm}$, leaves

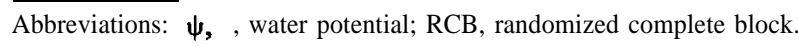


removed from the basal $6 \mathrm{~cm}$, and the basal $2.5 \mathrm{~cm}$ dipped into a $50 \%$ aqueous ethanol solution of $24.6 \mathrm{~mm} \mathrm{H}$-indole-3-butyric acid (IBA) for $5 \mathrm{sec}$. A 10-cm square of Parafilm was wrapped skirtwise around each cutting, $\approx .5 \mathrm{~cm}$ from its base, before the cutting's basal $4 \mathrm{~cm}$ was inserted into the tubes of propagation medium. The "skirt" was pulled down over the sides of the tubes to reduce water leakage into and evaporation from the tubes, while allowing air exchange within the medium. The cutting-tube units were weighed and then placed in RCB inside a walk-in, high-humidity propagation tent constructed within the glasshouse. The tent was covered with $0.1-\mathrm{mm}$-thick clear polyethylene film and $50 \%$ shade cloth supported by three hoops of 1.3-cm-o.d. pvc tubing bent to form a quonset. Relative humidity was maintained at or near $100 \%$ during daylight hours by three pneumatic atomizing nozzles (Delavan model 3060). Nozzle air pressure was maintained at $152 \mathrm{kPa}$ and water was provided through 5 -mm-id. tubing inserted into a plastic carboy. Tubes were weighed every 4 days to determine water uptake. There were 30 blocks of cuttings and five dowel-tube control blocks arranged in a RCB design to block out environmental difference within the tent.

Midday (1200 to $1400 \mathrm{HR}$ ) xylem $\psi$ was measured with a pressure chamber (Scholander et al., 1965) on two dates. Stem cuttings were destructively sampled from five blocks. Before insertion in the chamber, $1 \mathrm{~cm}$ of stem tissue was removed from the cutting base to eliminate variation due to internal stem blockages that may develop over time (Grange and Loach, 1983; Ikeda and Suzaki, 1986). When rooting or callusing occurred before $\psi$ measurement, that portion of the cutting base was removed. Stem cutting survival, the percentage of rooted cuttings, and the occurrence of basal rot were evaluated 24 Apr. on the remaining 20 blocks.

'Hino-Crimson' azalea. On 21 June 1989, 12.6-cm-long stem tip cuttings of Rhododendron 'Hino-Crimson' (Hino-Crimson azalea) were taken from container plants at a Suffolk, Va., nursery, placed on ice, and transported to Blacksburg. On 22 June, the cuttings were unpacked, trimmed acropetally to 10 $\mathrm{cm}$, and stripped of leaves. along the basal $6 \mathrm{~cm}$ of stem. The cuttings were basally dipped into a $50 \%$ aqueous ethanol solution of $6.15 \mathrm{~mm}$ IBA for $5 \mathrm{sec}$. The medium moisture treatments were applied and maintained as in the juniper experiment. Cutting $\psi$ was measured on four blocks three times: 27 June, 6 July, and 2 Aug. Cuttings for the remaining 16 blocks were evaluated for survival, basal rot, and rooting 8 weeks after insertion (18 Aug.). The cuttings were placed in a RCB design with 28 blocks of cuttings and five dowel-tube control blocks.

'Helleri' holly. On 29 Mar. 1989, 12-cm stem tip cuttings of holly were taken from container plants growing in a Suffolk nursery, placed on ice in a cooler, and transported to Blacksburg. On 31 Mar., the cuttings were trimmed basally to 11.5 $\mathrm{cm}$, stripped of leaves from the basal $4.5 \mathrm{~cm}$ of stem, and dipped basally into $24.6 \mathrm{~mm}$ IBA for $5 \mathrm{sec}$. Cuttings were placed in a RCB design as in the above experiments, with 26 blocks of cuttings, and four dowel-tube control blocks. Tubes were weighed every 4 days to determine cutting water uptake. $\psi$ 'was measured only once (14 Apr. 1989), because these cuttings initiated roots within 2 weeks. This experiment was repeated on 24 Apr., with stem cuttings taken from a landscape planting in Blacksburg. Twenty-six blocks of cuttings and four blocks of dowel-tube controls were established. $\psi$ was measured on four blocks of cuttings once every 6 days until rooting was evaluated (25 May). The experiment was repeated on 24 Aug., with stem cuttings taken from 12-liter container plants at a commercial nursery in
Piney River, Va. Twenty-eight blocks of cuttings and four blocks of dowel-tube controls were established. $\psi$ 'was measured once, and the experiment was terminated 21 Sept.

Statistical analyses. Percentage data, calculated by dividing the number of cuttings that rooted by the number of cuttings remaining at termination of the experiments, were transformed via arcsin [square root (percentage)] before statistical analysis. Tabular data were subjected to trend analysis using General Linear Models procedure of SAS (SAS Institute, Cary, N.C.). Best-fit regression models are presented for $\psi$ ، data.

\section{Results and Discussion}

Stem cutting quality and rooting percentages. In most cases, percent survival and adventitious rooting of stem cuttings were highest in the wettest propagation medium and lowest in the driest medium (Tables 1 and 2). Survival was high in juniper at all medium moisture levels, with $77 \%$ of cuttings in the lowest medium moisture level (125\%) alive and green 8 weeks after insertion (Table 1). It is possible that the surviving cuttings may have rooted later, since juniper cuttings may take $\geq 12$ weeks to root. Generally, survival of azalea and Japanese holly cuttings was low at the lowest moisture content. One exception is the 24 Aug. 'Helleri' trial, where $79 \%$ of the cuttings in the $125 \%$ treatment were alive after 3 weeks. However, the cuttings in this trial were of no economic value because basal rot had affected most of them and their rooting percentages were extremely low.

The variability in rooting percentages between species was expected. Stem cuttings of juniper are generally slower to root than those of either 'Helleri' holly or 'Hino-Crimson' azalea. However, the repeated experiments with 'Helleri' holly illustrated that rooting success can vary with time of year or growth stage of the stock plants (Table 2). 'Helleri' holly growth occurs

Table 1. Survival, basal rot, and rooting percentages of stem cuttings propagated in a peat/perlite medium at five moisture levels. Data are shown as actual percent.

\begin{tabular}{|c|c|c|c|}
\hline $\begin{array}{l}\text { Medium } \\
\text { moisture } \\
(\%)\end{array}$ & $\begin{array}{c}\text { Survival } \\
(\%)\end{array}$ & $\begin{array}{c}\text { Basal rot } \\
(\%)\end{array}$ & $\begin{array}{c}\text { Rooting } \\
(\%)\end{array}$ \\
\hline \multicolumn{4}{|c|}{ Blue Rug juniper } \\
\hline 125 & $77^{2}$ & 43 & 0 \\
\hline 250 & 95 & 24 & 0 \\
\hline 375 & 100 & 43 & 10 \\
\hline 500 & 100 & 43 & 5 \\
\hline 625 & 100 & 33 & 48 \\
\hline \multicolumn{4}{|l|}{ Significance } \\
\hline \multicolumn{4}{|c|}{ ( $P$ values of components) } \\
\hline Linear & 0.01 & 0.99 & 0.05 \\
\hline Quadratic & 0.03 & 0.99 & 0.40 \\
\hline \multicolumn{4}{|c|}{ Hino-Crimson azalea } \\
\hline 125 & 13 & 0 & 0 \\
\hline 250 & 19 & 0 & 0 \\
\hline 375 & 81 & 0 & 19 \\
\hline 500 & 100 & 0 & 38 \\
\hline 625 & 100 & 0 & 75 \\
\hline \multicolumn{4}{|l|}{ Significance } \\
\hline \multicolumn{4}{|c|}{$(P$ values of components) } \\
\hline Linear & 0.04 & 0.99 & 0.02 \\
\hline Quadratic & 0.70 & 0.99 & 0.33 \\
\hline
\end{tabular}

${ }^{\mathrm{z}}$ Percentage data transformed via arcsin [square root (proportion)] prior to statistical analysis. For Blue Rug juniper, $n=20$; for Hino-Crimson azalea, $\mathrm{n}=16$. 
Table 2. Survival, basal rot, and rooting percentages of 'Helleri' holly stem cuttings in a peat/perlite medium at five moisture levels. Data are shown as actual percent.

\begin{tabular}{|c|c|c|c|}
\hline $\begin{array}{l}\text { Medium } \\
\text { moisture } \\
(\%)\end{array}$ & $\begin{array}{c}\text { Survival } \\
(\%)\end{array}$ & $\begin{array}{c}\text { Basal rot } \\
(\%)\end{array}$ & $\begin{array}{l}\text { Rooting } \\
(\%)\end{array}$ \\
\hline \multicolumn{4}{|c|}{31 Mar.-22 Apr. 1989} \\
\hline 125 & $0^{\mathbf{z}}$ & 0 & 0 \\
\hline 250 & 74 & 0 & 26 \\
\hline 375 & 96 & 0 & 74 \\
\hline 500 & 91 & 0 & 74 \\
\hline 625 & 100 & 0 & 92 \\
\hline \multicolumn{4}{|c|}{ Significance } \\
\hline \multicolumn{4}{|c|}{ ( $P$ values of components) } \\
\hline Linear & 0.05 & 0.99 & 0.02 \\
\hline Quadratic & 0.18 & 0.99 & 0.18 \\
\hline \multicolumn{4}{|c|}{27 Apr.-26 May 1989} \\
\hline 125 & 30 & 0 & 20 \\
\hline 250 & 80 & 20 & 60 \\
\hline 375 & 90 & 0 & 60 \\
\hline 500 & 100 & 20 & 90 \\
\hline 625 & 100 & 20 & 70 \\
\hline \multicolumn{4}{|l|}{ Significance } \\
\hline \multicolumn{4}{|c|}{ ( $P$ values of components) } \\
\hline Linear & 0.01 & 0.42 & 0.10 \\
\hline Quadratic & 0.12 & 0.99 & 0.23 \\
\hline \multicolumn{4}{|c|}{24 Aug.-21 Sept. 1989} \\
\hline 125 & 79 & 50 & 0 \\
\hline 250 & 75 & 75 & 0 \\
\hline 375 & 75 & 71 & 4 \\
\hline 500 & 83 & 88 & 4 \\
\hline 625 & 88 & 83 & 8 \\
\hline \multicolumn{4}{|c|}{ Significance } \\
\hline \multicolumn{4}{|c|}{ ( $P$ values of components) } \\
\hline Linear & 0.04 & 0.09 & 0.05 \\
\hline Quadratic & 0.06 & 0.37 & 0.91 \\
\hline
\end{tabular}

${ }^{\mathrm{Z}}$ Percentage data transformed via arcsin [square root (proportion)] prior to statistical analysis. For 31 Mar., $n=22 ; 27$ Apr., $n=10 ; 22$ Aug., $\mathrm{n}=24$.

in flushes throughout the growing season, and it usually is recommended to take these cuttings between the periods of shoot growth (Dirr and Heuser, 1987). Within this cultivar, the highest rooting percentages dropped from $\approx \$ 90 \%$ for dormant cuttings (exhibiting no visible bud activity) taken 31 Mar. and 27 Apr., to only $8 \%$ for cuttings taken in August, when a shoot flush was beginning.

In no case was the incidence of basal rot significantly related to the percentage of moisture in the propagation medium (Tables 1 and 2). Instead, basal rot in this study seemed related more to the growth stage of the cutting. For example, basal rot of 'Helleri' holly cuttings taken in August was much more severe than on cuttings taken in March or April (Table 2). Increasing the percentage of water in the propagation medium seemed to aggravate basal rotting of the August 'Helleri' cuttings, but only at $P=0.09$. Although they were inserted into tubes that were at least partially filled with water, cuttings in the medium with the highest moisture treatment content did not rot significantly more than at lower moisture levels.

Water potential. The midday xylem $\psi$ of stem cuttings was highest at the highest medium moisture level and lowest at the lowest medium moisture level (Fig. 1). Only data from the first date of $\psi$ measurement are presented for each species, since $\psi$ trends were similar on subsequent measurement dates. The $\psi$
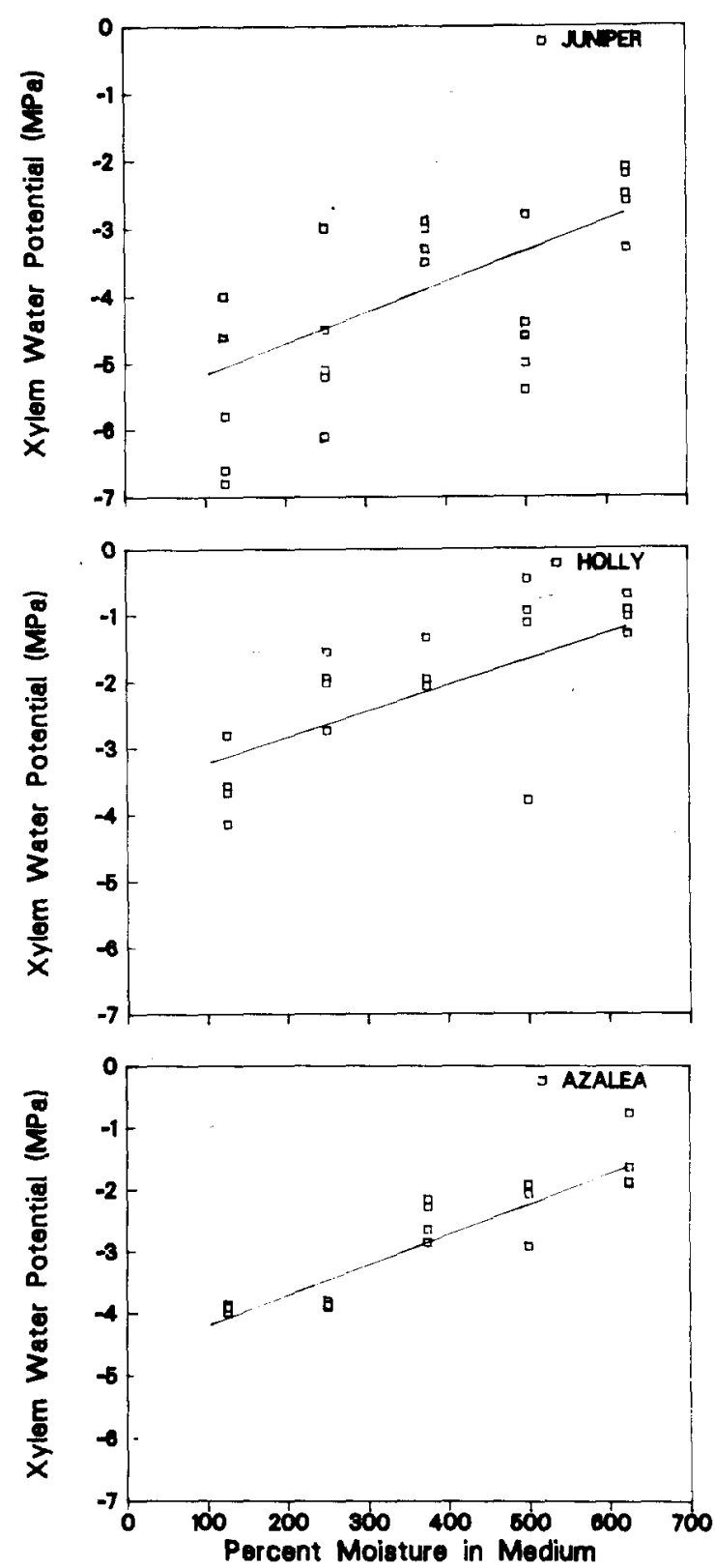

Fig. 1. Water potential of stem cuttings after insertion into a 1 peat : 1 perlite propagation medium maintained at five moisture levels. Blue Rug juniper: 14 days after insertion, with five cuttings measured per moisture level, $\mathrm{Y}=-6.048+0.005 \mathrm{x}, R^{2}=0.45$, $P=0.0002$. 'Helleri' holly: 4 days after sticking, with four cuttings measured per moisture level, $\mathrm{Y}=-3.68+0.004 \mathrm{x}, R^{2}=0.54$, $P=0.0007$. 'Hino-Crimson' azalea: 5 days after sticking, with four cuttings measured per moisture level, $\mathrm{Y}=-4.71+0.005 \mathrm{x}$, $R^{2}=0.84, P=0.0001$.

of cuttings that had as few as one or two roots was much higher than the $\psi$ of unrooted cuttings (data not shown). Apparently, water stress was reduced as resistance to water uptake was reduced as a result of rooting (Loach, 1977).

Even at the highest medium moisture percentage, stem cutting $\psi$ ibecame quite negative, often much below what is considered the turgor loss point for most plants $(-1.5$ to $-2.0 \mathrm{MPa})$ (Kramer, 1983). The $\psi$ of juniper cuttings at all treatment levels was quite low relative to the other species. Apparently, juniper maintains a relatively low $\psi$ as a mature, rooted plant. Pre-insertion stem cutting $\psi$ averaged $-1.52 \mathrm{MPa}$ (mean of five cuttings) 
for Blue Rug juniper and - 0.36 MPa and - 0.32 MPa (mean of four cuttings) for 'Helleri' holly and 'Hino-Crimson' azalea, respectively. As noted, $\psi$ for azalea and holly cuttings decreased to very low levels within 5 days after insertion into the medium (Fig. 1). Using thermocouple psychrometry, Loach (1977) found that the mean leaf $\psi$ of rhododendron stem cuttings propagated under intermittent mist decreased from - 1.37 MPa 3 days after insertion to $-1.97 \mathrm{MPa} 44$ days after insertion. In the present experiment, $\psi$ of cuttings at all medium moisture levels was more negative than that found by Loach (1977). Differences between our studies may be due to differences in propagation conditions and species tested. Leaf and air temperatures may be much higher under a high humidity propagation system than under intermittent mist (Slezinski and Davidson, 1973; Wright et al., 1978). Higher leaf temperatures could increase water stress, thereby decreasing stem cutting $\psi$.

Water uptake by stem cuttings. Stem cuttings in the wettest medium generally showed the greatest amount of water uptake (Tables 3 and 4). This result is in agreement with the findings of Grange and Loach (1983) that water uptake by stem cuttings is limited by the availability of water to the cut stem base. Our data also show that water uptake by cuttings is greatest during the first 4 days of propagation, followed by a period of lower water absorption from the propagation medium until adventitious roots formed. The latter increase in uptake by 'Helleri' holly cuttings occurred between the 3rd and 4th weeks after insertion, corresponding to the period in which rooting was noted.

Table 3. Water uptake by 'Helleri' holly stem cuttings from a peat/ perlite medium at five moisture levels (cuttings inserted $27 \mathrm{Apr}$.).

\begin{tabular}{|c|c|c|c|c|c|c|}
\hline \multirow{3}{*}{$\begin{array}{l}\text { Medium } \\
\text { moisture } \\
(\%) \\
\end{array}$} & \multicolumn{6}{|c|}{ Water uptake $(\mathrm{g})^{\mathbf{z}}$} \\
\hline & \multicolumn{6}{|c|}{ Days after sticking } \\
\hline & 4 & 8 & 12 & 16 & 23 & 27 \\
\hline 125 & 0.16 & 0.12 & 0.11 & 0.06 & 0.02 & 0.03 \\
\hline 250 & 0.28 & 0.17 & 0.16 & 0.06 & 0.32 & 0.42 \\
\hline 375 & 0.34 & 0.18 & 0.12 & 0.07 & 0.31 & 0.42 \\
\hline 500 & 0.20 & 0.20 & 0.20 & 0.05 & 0.31 & 0.42 \\
\hline 625 & 0.41 & 0.35 & 0.21 & 0.08 & 0.17 & 0.53 \\
\hline \multirow{2}{*}{\multicolumn{7}{|c|}{$\begin{array}{l}\text { Significance } \\
\text { ( } P \text { values of components })\end{array}$}} \\
\hline & & & & & & \\
\hline Linear & 0.08 & 0.02 & 0.12 & 0.79 & 0.18 & 0.03 \\
\hline Quadratic & 0.94 & 0.37 & 0.83 & 0.82 & 0.01 & 0.32 \\
\hline
\end{tabular}

${ }^{\mathrm{z}}$ Mean uptake of 10 cuttings, over previous 4 days. Linear and quadratic $P$ values for uptake data over time were $<0.05$ except for the $125 \%$ treatment.

Table 4. Water uptake by Blue Rug juniper stem cuttings from a peat/perlite medium at five moisture levels.

\begin{tabular}{|c|c|c|c|c|c|c|c|c|c|c|}
\hline \multirow{3}{*}{$\begin{array}{l}\text { Medium } \\
\text { moisture } \\
(\%)\end{array}$} & \multicolumn{10}{|c|}{ Water uptake $(\mathrm{g})^{\mathbf{z}}$} \\
\hline & \multicolumn{10}{|c|}{ Days after sticking } \\
\hline & 4 & 8 & 12 & 16 & 24 & 28 & 32 & 38 & 42 & 46 \\
\hline 125 & 0.70 & 0.15 & 0.23 & 0.28 & 0.32 & 0.21 & 0.18 & 0.14 & 0.14 & 0.22 \\
\hline 250 & 0.50 & 0.19 & 0.19 & 0.18 & 0.36 & 0.19 & 0.23 & 0.25 & 0.11 & 0.28 \\
\hline 375 & 1.11 & 0.38 & 0.46 & 0.39 & 0.59 & 0.32 & 0.33 & 0.52 & 0.50 & 0.62 \\
\hline 500 & 1.04 & 0.34 & 0.52 & 0.51 & 0.77 & 0.42 & 0.34 & 0.39 & 0.29 & 0.51 \\
\hline 625 & 2.18 & 0.42 & 0.67 & 0.92 & 1.16 & 0.82 & 0.62 & 1.34 & 1.25 & 1.87 \\
\hline \multirow{2}{*}{\multicolumn{11}{|c|}{$\begin{array}{l}\text { Significance } \\
\quad(P \text { values of components })\end{array}$}} \\
\hline & & & & & & & & & & \\
\hline Linear & 0.01 & 0.01 & 0.01 & 0.01 & 0.01 & 0.01 & 0.01 & 0.01 & 0.01 & 0.01 \\
\hline Quadratic & 0.01 & 0.48 & 0.30 & 0.01 & 0.05 & 0.01 & 0.25 & 0.02 & 0.02 & 0.04 \\
\hline
\end{tabular}

The high initial water uptake by cuttings may be due to the continued transpirational water loss through stomata that have not yet responded to the stress of propagation. The application of greater quantities of water to stem cuttings during this period could help reduce water stress. Our results indicate that the wetter medium, which may result from heavy water application during propagation, does not necessarily adversely affect rooting. Evans (1952) and later Grange and Loach (1983) noted that water uptake by cut stems became restricted by gum-like residues that formed near the stem base shortly after excision from the stock plant. Ikeda and Suzaki (1986) have shown that water flow of cuttings was caused by blockage of vessel lumens with tyloses. These factors may have contributed to the reduction in uptake measured after the first 4 days of propagation, and may further contribute to the reduction in stem cutting $\psi$ over time.

An increase in contact between the cut stem base and the water in the medium probably accounted for greater water uptake by stem cuttings in the higher medium moisture treatments (Grange and Loach, 1983). The duration and extent of this contact could control stem cutting $\psi$ and adventitious rooting. In our work, $\psi$ was less negative in cuttings propagated in the highest medium moisture levels, probably because their water demands were met by the presence of free water. Therefore, water stress during propagation can be reduced not only by reducing leaf-air vapor pressure deficit but also by maintaining high medium moisture levels. Limiting water stress in stem cuttings increases the possibility of adventitious rooting (Evans, 1952; Loach, 1977).

The level of moisture in a propagation medium influences the ability of stem cuttings to absorb water and produce adventitious roots. The availability of moisture in a propagation medium at least partially controls the ability of a stem cutting to absorb enough water to offset transpirational and nonstomatal water losses. A standard 1 peat :1 perlite medium under intermittent mist may contain $400 \%$ to $500 \%$ moisture on a dry-weight basis. We found that stem cuttings inserted into a relatively wet propagation medium (625\%) exhibited greater water absorption, less negative $\psi$, and greater adventitious rooting percentages than cuttings propagated at lower percent moisture levels. Cuttings in a finer-textured medium may have exhibited basal rot and reduced rooting under conditions of excessive moisture. However, within the range of moisture and species tested here, a reduction in stem cutting quality due to basal rotting was not a direct result of high moisture levels in the propagation medium, even when the cuttings were at least partially submerged in water. The basal rotting of stem cuttings appeared to be more closely linked to the growth stage of the cutting tissue.

\section{Literature Cited}

Dirr, M.A. and C.W. Heuser. 1987. The reference manual of woody plant propagation. Varsity Press, Athens, Ga.

Evans, H. 1952. Physiological aspects of the propagation of cacao from cuttings. Rpt. XIIIth Intl Hort. Congr. 2:1179-1190.

Grange, R.I. and K. Loach. 1983. The water economy of unrooted leafy cuttings. J. Hort. Sci. 58:9-17.

Ikeda, T. and T. Suzaki. 1986. Influence of hydraulic conductivity of xylem on water status of cuttings. Can. J. For. Res. 161:98-102.

Kramer, P.J. 1983. Water relations of plants. Academic, New York. p. 390-415.

Loach, K. 1977. Leaf water potential and the rooting of cuttings under mist and polyethylene. Physiol. Plantarum 40:191-197.

Loach, K. 1985. Rooting of cuttings in relation to the propagation medium. Proc. Intl Plant Prop. Soc. 35:472-485.

Long, J.C. 1933. The influence of rooting media on the character of 
roots produced by cuttings. Proc. Amer. Soc. Hort. Sci. 29:352355.

Scholander, P. F., H.T. Hammel, E.D. Bradstreet, and E.M. Hermmingsen. 1965. Sap pressure in vascular plants. Science 148:339-346.

Slezinski, J. and H. Davidson. 1973. Vapor pressure deficit and polyethylene in plant propagation. Proc. Intl. Plant Prop. Soc. 23:238241.

Soffer, H. and D.W. Burger. 1988. Effects of dissolved oxygen con- centrations in aerohydroponics on formation and growth of adventitious roots. J. Amer. Soc. Hort. Sci. 113:218-221.

Tilt, K.M. and T.E. Bilderback. 1987. Physical properties of propagation media and their effects on rooting of three woody ornamentals. HortScience 22:245-247.

Wright, R.D., F.H. Blazich, and C.H. Gilliam. 1978. Comparison of rooting with high-humidity and mist propagation systems. Amer. Nurseryman 148(8):10,77. 